\title{
Low-Level Jet Winds at Green River, Utah
}

\author{
Laurence J. Rider and Manuel ArMendariz \\ Atmospheric Sciences Laboratory, White Sands Missile Range, N. Mex. \\ 22 April 1966 and 13 June 1966
}

\section{Introduction}

The vertical profile of horizontal wind speed sometimes shows a relatively sharp peak or "nose" within the lowest $5000 \mathrm{ft}$ of the atmosphere. Such low-level maxima apparently achieve greatest development and occur more frequently in parts of the central and southern plains area of the United States during the summertime between midnight and sunrise and at about 1500$2500 \mathrm{ft}$ above ground level.

During 1963, a considerable number of nighttime and early morning radiosonde soundings were made at Green River, Utah, and a few soundings were made during these hours in 1964 and 1965. Wind data from these soundings indicated a number of significant low-level wind maxima. It is the purpose of this note to show some evidence of low-level jets at Green River, make some comments concerning their development, and point out their importance and the need for a more thorough study of the phenomenon.

The low-level jet is of great interest from a theoretical viewpoint since its explanation must involve turbulent mass exchange within the planetary boundary layer. It also has very important practical interest. Of primary concern is the effect of such sharp low-level wind profiles and the associated wind shear upon rockets launched at Green River.

\section{Discussion}

Examination of 195 nighttime radiosonde soundings revealed 32 cases of low-level wind maxima considered 
significant. Twenty-seven of the thirty-two cases are from the year 1963, when most of the data were collected.

In eleven of the cases the wind was northerly with an average direction of $017 \mathrm{deg}$, ranging from 338-035 deg. The wind direction in the other 21 cases was southerly with an average of $206 \mathrm{deg}$, with a range of 132-248 deg. The favored directions of 017 and 206 are perhaps due to the topography of the area since the Green River and Colorado River Valleys are generally orientated on a northeast to southwest line as shown in Fig. 1.

The low-level jet winds were southerly in the data analyzed by Barad (1961), Hoecker (1965) and Wexler (1961). One of the prerequisites for development of a low-level jet is a steady and significant horizontal pressure gradient force, and it is suggested that this condition at Green River occurs most often when the wind direction is from south-southwest or north. The most favorable time for low-level jets to develop appears to be late at right when there is a minimum of vertical momentum transfer. The release times of the nighttime radiosondes were 2300,0200 and $0500 \mathrm{MST}$. The surface data were recorded at $4280 \mathrm{ft} \mathrm{MSL}$, and the release point was within $500 \mathrm{ft}$ of the meteorological tower location shown in Fig. 1. In a few cases the next level at which data was computed and recorded was at 4500 $\mathrm{ft}$, but in most cases it was at $5000 \mathrm{ft}$. Above $5000 \mathrm{ft}$ the data was available at $500-\mathrm{ft}$ intervals. Data reduction and recording techniques resulted in somewhat gross data since wind and temperature was averaged over rather thick layers. This may account for the rather large difference in height in those cases with a surface temperature inversion at the time of a low-level wind maximum where the nose of the wind profile is approximately $1000 \mathrm{ft}$ higher than the top of the inversion. This is a greater separation in height than is generally observed over the Great Plains area (Gerhardt, 1961; Barad, 1961; Hoecker, 1965; Means, 1952). It is also possible that the extreme roughness of the terrain in the: Green River area is responsible for some of this difference. The average height of the nose of the low-level jet for the 32 cases was $2500 \mathrm{ft}$ with a range of $1100-3200 \mathrm{ft}$. The average height of the 21 southerly cases was $2300 \mathrm{ft}$, ranging from $1100-3200 \mathrm{ft}$, and the average height of the 11 northerly cases was $2700 \mathrm{ft}$, with variations from $1700-3200 \mathrm{ft}$.

Seven of the 32 cases showed wind speeds of 30-40 $\mathrm{mph}$, and these occurred in the months of May, June and July. The occurrence of these maxima satisfies some of the prerequisites for the low-level jet development, which is an intense summer sun that produces strong diurnal cycles of convective turbulence. Available meteorological data corresponding to the times of the low-level wind maxima were examined, and skies were basically clear in the cases considered in this report.

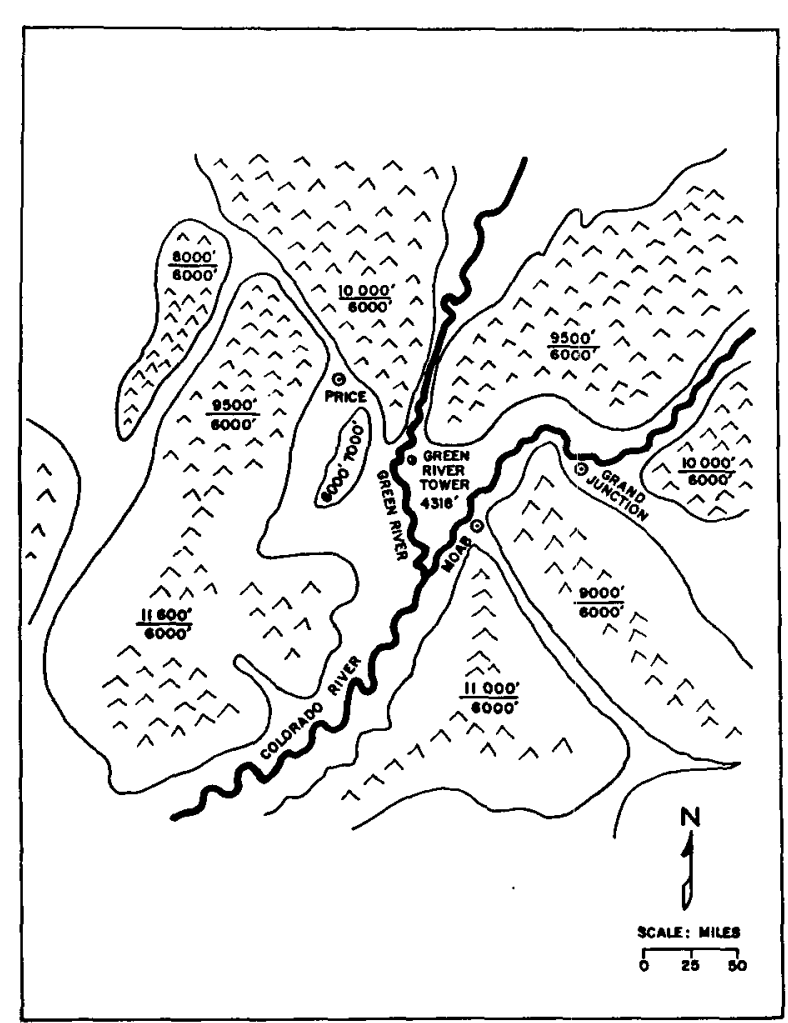

FIG. 1. Topography of meteorological tower site and surrounding area.

In seven of the 32 cases, sufficient meteorological data was available at the required time to make a reasonably accurate evaluation of the $850-\mathrm{mb}$ level geostrophic wind. In these cases the low-level jet wind was supergeostrophic.

The evolution of the wind profile as the low-level jet develops is probably somewhat irregular, being marked by fluctuations in the strength of the wind maximum. Because of the paucity of data, the development process and dissipation of the surprisingly strong wind cannot be completely shown in this study. The four examples that follow show the change in wind and temperature profiles within a few hours. On the night of 3 June 1963 at 2300 MST (top Fig. 2), the height of the nose was $2400 \mathrm{ft}$ with a wind of $38 \mathrm{mph}$ from $195 \mathrm{deg}$. Six hours later at 0500 on 4 June the height had increased to $2700 \mathrm{ft}$ with a wind of $39 \mathrm{mph}$ from $192 \mathrm{deg}$.

The 0200 profile (not shown) was nearly the same shape but with the nose of the jet at a height of $2500 \mathrm{ft}$ and a wind of $34.5 \mathrm{mph}$. At 2300 on 9 May 1963 (bottom Fig. 3) the height of the nose was $2700 \mathrm{ft}$, and at 0200 on 10 May the height was $3200 \mathrm{ft}$. At 2300 MST 4 September 1963 (top Fig. 4), the height of the nose was $1700 \mathrm{ft}$, and at 0200 on 5 September, it was $2200 \mathrm{ft}$. At 2345 on 23 September 1963 (bottom Fig. 4), the nose was $2700 \mathrm{ft}$ and apparently remained the same through 0200 on 24 September. 

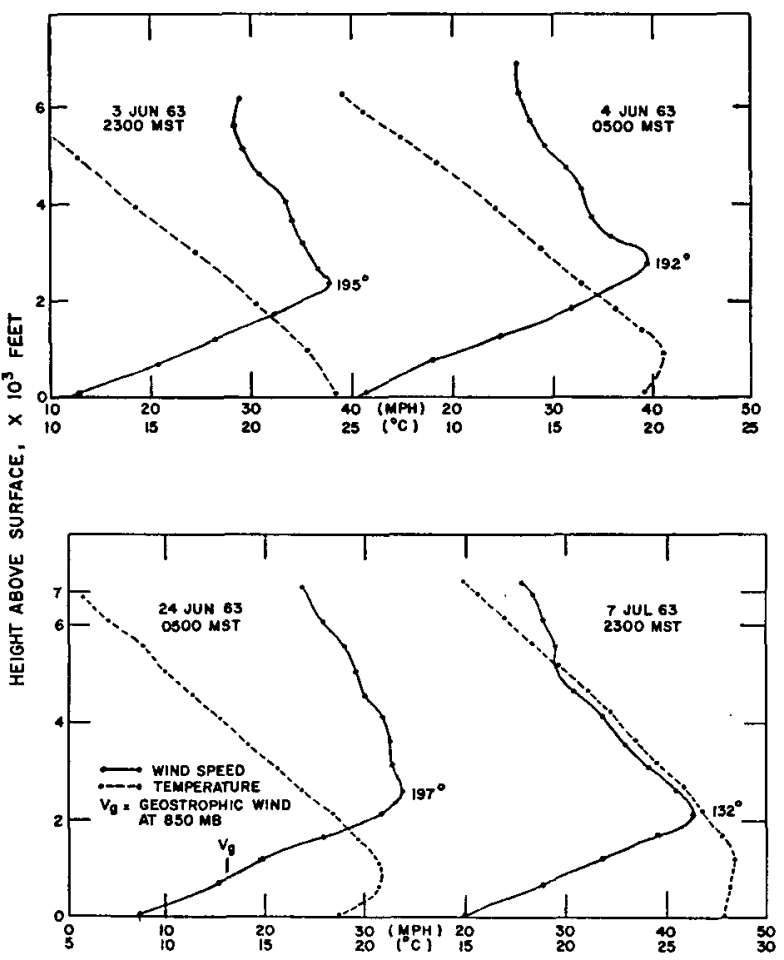

Fig. 2. Wind speed and temperature profiles.

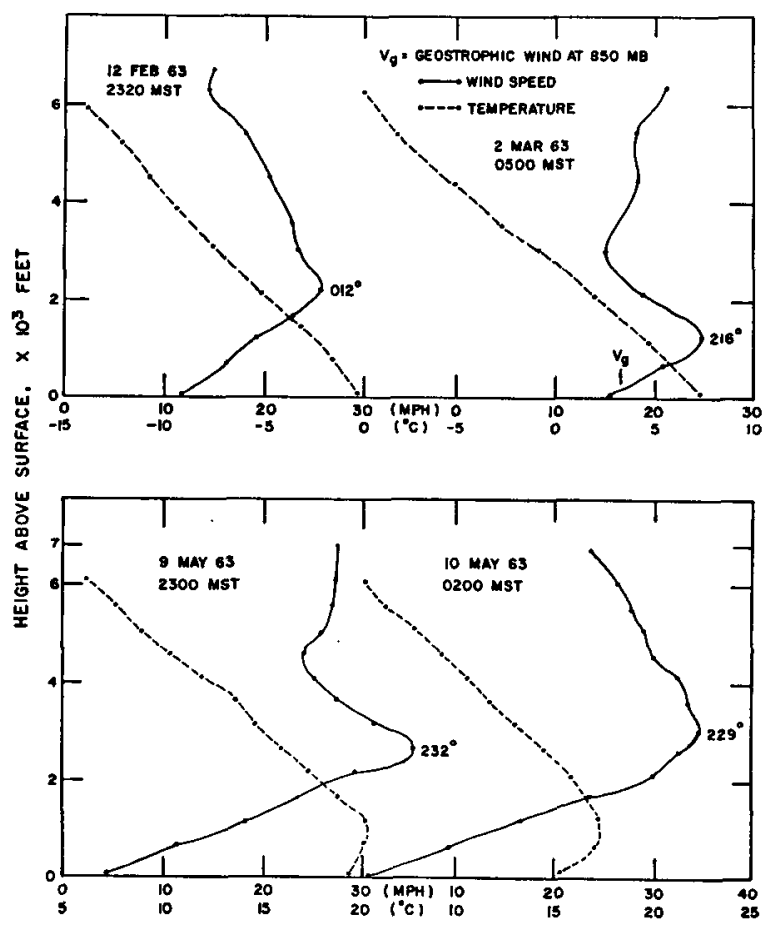

FIG. 3. Wind speed and temperature profiles.

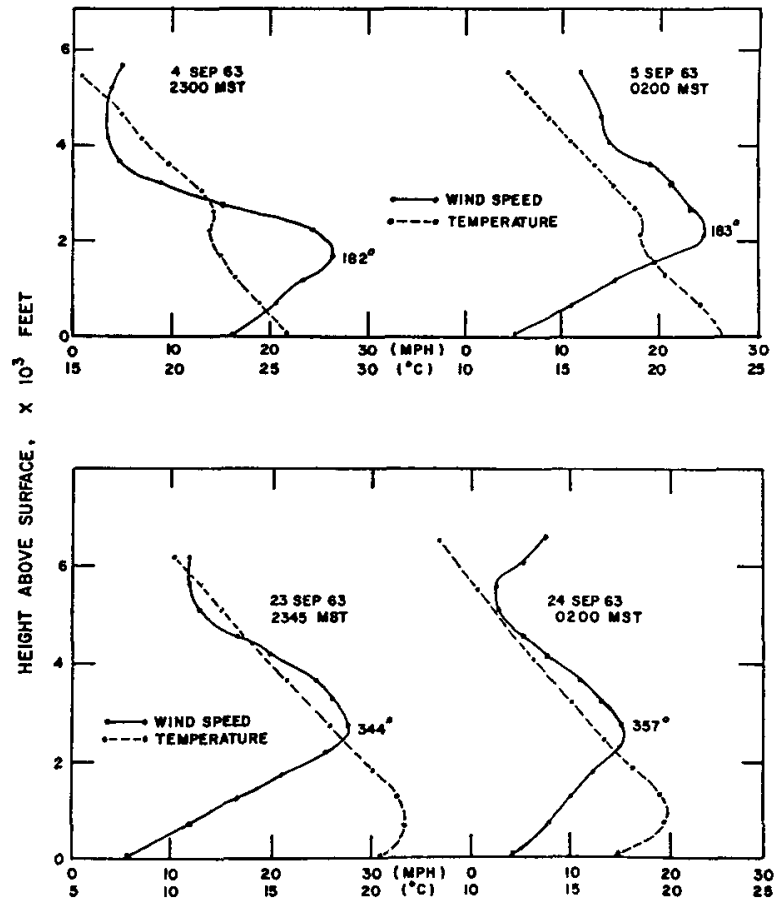

FIG. 4. Wind speed and temperature profiles.

A few cases (two of which are shown at the top of Fig. 3) of a significant low-level wind maximum were observed with lapse temperature conditions. This was also observed at White Sands Missile Range (Rider, 1966).

\section{Conclusions}

Significant low-level jet winds occur on occasion at Green River, Utah. Because of the limited wind and temperature data at this site, particularly nighttime data, statements about the evolution of the low-level jet are somewhat limited. It appears, however, that such a phenomenon is less common and the shear and wind speeds in the ones which do occur in this area are less than those generally observed in the low-level jets in parts of the Great Plains. The height of the nose appears to be a little higher and significant low-level maxima occur with lapse temperature conditions. The low-level jets are most likely to develop on cloudless nights when there is a significant sustained pressure gradient force. Considerable wind and temperature data collected in a desirable manner will be required for a more complete and systematic analysis of this very complex phenomenon.

\section{REFERENCES}

Barad, M. L., 1961: Low altitude jet streams. Sci. Amer., 205, 120-131.

Gerhardt, J. R., 1961: An example of a nocturnal low-level jet stream. J. Atmos. Sci., 19, 116-118. 
Hoecker, W. H., 1965: Comparative physical behavior of southerly boundary-layer wind jets. Mon. Wea. Rev., 93, 133-144. Means, L. L., 1952: On thunderstorm forecasting in the central United States. Mon. Wea. Rev., 80, 165-189.
Rider, L. J., 1966: Low-level jet at White Sands Missile Range. J. Appl. Meteor., 5, 283-287.

Wexler, H., 1961: A boundary layer interpretation of the low-level jet. Tellus, 13, 369-378. 